\title{
NOVO MARCO LEGAL DA INOVAÇÃO NO BRASIL: BREVE ANÁLISE DOS REFLEXOS DAS ALTERAÇÕES NA LEI No 10.973/2004 PARA OS NÚCLEOS DE INOVAÇÃO TECNOLÓGICA
}

\author{
NEW LEGAL FRAMEWORK OF INNOVATION IN BRAZIL: A BRIEF ANALYSIS \\ OF THE REFLEXES OF CHANGES IN LAW 10.973 / 2004 FOR INNOVATION \\ TECHNOLOGY CENTERS
}

\author{
${ }^{1}$ Bruno Costa Marinho \\ ${ }^{2}$ Lenilton Duran Pinto Corrêa
}

\begin{abstract}
RESUMO
Este trabalho aborda as alterações introduzidas na Lei de Inovação e os possíveis reflexos no trabalho desenvolvido nos Núcleos de Inovação Tecnológica (NIT). Tal abordagem se faz necessária em face da recente publicação da Lei $\mathrm{n}^{\circ}$ 13.243/2016, que dispõe sobre estímulos ao desenvolvimento científico, à pesquisa, à capacitação científica e tecnológica e à inovação. Foram alteradas, além da Lei $\mathrm{n}^{\circ} 10.973 / 2004$, outras oito leis federais, com a finalidade de propiciar um ambiente cada vez mais favorável à inovação. O trabalho será desenvolvido por intermédio de revisão bibliográfica, pesquisa documental da legislação federal e atos normativos afetos ao tema proposto.
\end{abstract}

Palavras-chave: Inovação, Propriedade intelectual, Núcleos de inovação tecnológica

\begin{abstract}
This work addresses the changes in the Innovation Law and the possible impacts on the work of the Technological Innovation Centers (NIT). Such an approach is necessary considering the recent publication of Law No. 13.243/2016, which provides incentives to scientific development, research, scientific and technological capacity and innovation. Besides Law $n^{\circ}$ 10.973/2004, eight other federal laws were changed, in order to provide an increasingly favorable environment for innovation. The work will be developed through literature review, document search of federal laws and normative acts affect to the proposed theme.
\end{abstract}

Keywords: Innovation, Intellectual property, Technological innovation centers

${ }^{1}$ Mestre em Direito Ambiental pela Universidade do Estado do Amazona - UEA, Manaus, Amazonas, (Brasil). Adjunto da Agência de Gestão e Inovação Tecnológica do Exército Brasileiro. E-mail: bcmarinho@ @mail.com ${ }^{2}$ Mestrando em Propriedade Intelectual e Inovação pelo Instituto Nacional Propriedade Industrial - INPI, São Paulo, (Brasil). Membro da Associação Brasileira de Propriedade Intelectual E-mail: leniltonduran@ hotmail.com 


\section{INTRODUÇÃO}

Antes de examinar as alterações e inclusões de dispositivos da Lei 13.243, de 11 de janeiro de 2016, na Lei de Inovação, cumpre salientar que um novo "marco constitucional" sobre esta temática foi inserido na Lei Maior por intermédio da EC 85, a qual alterou e adicionou dispositivos na Constituição Federal para, nos termos da aludida emenda, "atualizar o tratamento das atividades de Ciência, Tecnologia e Inovação”.

Dentre as modificações introduzidas, podemos citar: a competência comum da União, dos Estados, do Distrito Federal e dos Municípios para proporcionar o acesso à cultura, à educação, à ciência, à tecnologia, à pesquisa e à inovação (art. 23, inciso V); a competência legislativa concorrente para dispor sobre educação, cultura, ensino, desporto, ciência, tecnologia, pesquisa, desenvolvimento e inovação (art. 24, inciso IX); a possibilidade de transposição, remanejamento ou transferência de recursos de uma categoria de programação para outra com o objetivo de viabilizar projetosde Ciência, Tecnologia e Inovação, mediante ato do Poder Executivo, sem necessidade da prévia autorização legislativa (art. 167, § $5^{\circ}$ ); atribuição ao Sistema Único de Saúde (SUS) para incrementar, em sua área de atuação, o desenvolvimento científico e tecnológico e a inovação (art. 200, inciso V); a possibilidade de apoio financeiro do Poder Público para as atividades de pesquisa, de extensão e de estímulo e fomento à inovação, realizadas em universidades e/ou instituições de educação profissional e tecnológica públicas (art. 213, § $2^{\circ}$ ); e as alterações feitas no Capítulo IV, do TÍTULO VIII, a respeito da Ciência, Tecnologia e Inovação (arts. 218 a 219-B).

A partir desta última alteração constitucional citada, cumpre observar que o Capítulo IV - "Da Ciência, Tecnologia e Inovação" encontra-se inserido no TÍTULO VIII - "Da Ordem Social”, da Carta Magna. Neste sentido, o art. $1^{\circ}$ da Lei de Inovação, com a nova redação introduzida pela Lei $\mathrm{n}^{\mathrm{o}} 13.243$, de 2016, passa a tratar a esfera social como um dos objetivos a serem alcançados junto ao desenvolvimento tecnológico.

Contudo, por se tratar de uma lei que tem por objetivo específico tratar da inovação, a Lei ${ }^{\circ} 10.973$, de 2004, agora com as alterações trazidas pela Lei ${ }^{\circ} 13.243$, de 2016, está sendo considerada como novo Marco da Ciência, Tecnologia e Inovação.

Importante ressaltar que, apesar de ter modificado 19 dos 29 artigos da Lei da Inovação, além de ter incluído outros 11 artigos na mesma lei, a Lei nº 13.243, de 2016, modificou ainda outras oito leis, a seguir listadas, que, no entanto, não serão objeto do presente trabalho: Lei no 6.815, de 1980 (Estatuto do Estrangeiro); Lei nº 8.010, de 1990 (Dispõe sobre importação de bens para pesquisa científica e tecnológica); Lei $\mathrm{n}^{\circ} 8.032$, de 
1990 (Dispõe sobre impostos de importação); Lei no 8.666, de 1993 (Institui normas para licitações e contratos); Lei no 8.745, de 1993 (Dispõe sobre contratações temporárias); Lei n $^{\circ}$ 8.958, de 1994 (Dispõe sobre as fundações de apoio); Lei nº 12.462, de 2011 (Institui o regime diferenciado de contratações); e Lei $\mathrm{n}^{\circ}$ 12.772, de 2012 (Dispõe sobre o magistério federal).

Segundo o Manual de $\mathrm{Oslo}^{1}$, o conceito de inovação encerra uma concepção muito abrangente, compreendendo quatro grandes grupos: inovações de produto; inovações de processo; inovações organizacionais; e inovações de marketing. Assim dispõe a letra desta importante publicação da Organização para Cooperação e Desenvolvimento Econômico (OCDE):

\begin{abstract}
Inovações de produto envolvem mudanças significativas nas potencialidades de produtos e serviços. Incluem-se bens e serviços totalmente novos e aperfeiçoamentos importantes para produtos existentes. Inovações de processo representam mudanças significativas nos métodos de produção e de distribuição.

(...)

As inovações organizacionais referem-se à implementação de novos métodos organizacionais, tais como mudanças em práticas de negócios, na organização do local de trabalho ou nas relações externas da empresa. As inovações de marketing envolvem a implementação de novos métodos de marketing, incluindo mudanças no design do produto e na embalagem, na promoção do produto e sua colocação, e em métodos de estabelecimento de preços de bens e de serviços.
\end{abstract}

Xavier et al (2014, p. 22) aduzem que podem ser identificados até vinte tipos diferentes de inovação, cujos resultados podem ser verificados em, no mínimo, seis tipos de iniciativas: “(1) um novo produto ou serviço; (2) um novo processo organizacional; (3) um novo modelo de gestão organizacional; (4) uma nova abordagem de marketing; (5) um novo modelo de comercialização; e (6) um novo modelo de negócios.”

Sob a ótica da alteração introduzida, o conceito enunciado pela redação original da Lei $\mathrm{n}^{\mathrm{o}}$ 10.973, em sua gênese, permaneceu o mesmo: “introdução de novidade ou aperfeiçoamento no ambiente produtivo e social que resulte em novos produtos, serviços ou processos (...)” (art. 2o, IV, primeira parte).

Entretanto, houve uma preocupação do legislador em sublinhar que também considerase como inovação "a agregação de novas funcionalidades ou características a produto, serviço ou processo já existente que possa resultar em melhorias e em efetivo ganho de qualidade ou desempenho" (art. $2^{\circ}$, IV, in fine).

Neste passo, alguns autores que se debruçaram sobre o conceito de inovação observam que este instituto é "difícil de definir e mais ainda de medir. Normalmente, pensa-se na

1 Conforme observa Tigre (2014, p. 74), o Manual de Oslo é a publicação de referência mundial para analisar o processo de gestão da inovação. 
inovação como a criação de um produto ou processo melhor. No entanto, ela poderia ser tão simplesmente a substituição de um material por outro (...)" (Mattos e Guimarães, 2012, p. 35). Kotler e Bes (2011, p.18), compartilhando do mesmo entendimento, alertam para o fato de que a inovação não necessariamente acarreta saltos gigantes em relação ao estágio tecnológico anterior ("inovação radical”). Desta forma, a inovação gradual, ocorrida passo a passo, também deve ser considerada como de fato uma inovação, sendo tão ou mais necessária que a versão radical.

Como exemplo de inovação que não pode ser considerada radical, pode ser até entendida como simples ("inovação incremental"), do ponto de vista de sua fabricação, mas que trouxe grande facilidade para o trabalho doméstico em grande parte dos lares brasileiros e estrangeiros é o Modelo de Utilidade patenteado no INPI, sob o número 71.404, pela brasileira Therezinha Beatriz Alves de Andrade Zorowich, que se configura no recipiente para lavagem e escorrimento de arroz.

Esse exemplo de inovação poderia ter passado despercebido pela inventora, uma cirurgiã dentista, que, por características pessoais próprias teve a visão de que esse produto seria passível de ser patenteado. Caso não tivesse feito o depósito da patente, perderia a novidade e cairia em domínio público, sem auferimento de vantagens pecuniárias pela inventora.

Neste sentido, o presente trabalho tem por objetivo apresentar as principais alterações que a Lei $\mathrm{n}^{\circ}$ 13.243, de 11 de janeiro de 2016, trouxe para o funcionamento dos Núcleos de Inovação Tecnológica. Para tal, foi realizada uma revisão bibliográfica, apresentando o entendimento dos doutrinadores acerca das atribuições dos NIT e verificando de que forma essas alterações legislativas poderão influenciar em suas atividades.

\section{NÚCLEOS DE INOVAÇÃO TECNOLÓGICA}

A fim de gerenciar os processos de inovação, por intermédio da Lei no 10.973 , de 2004, foram instituídos os Núcleos de Inovação Tecnológica (NIT), ligados a uma ou mais Instituições de Ciência e Tecnologia (ICT), com a finalidade de gerir suas políticas de inovação.

Conforme Martins (2012, p. 229) a implantação dos NIT foi precedida de ações indutoras "do MCT desde os anos 80, quando foram implementados: a Rede de Núcleos de Informação Tecnológica Industrial, o Núcleo Básico de Informação em Patentes, no INPI, e a disseminação do banco de patentes pelos 22 Núcleos então existentes.” 
Ainda no magistério de Martins (2012, p. 229), foram previstos três modelos de Núcleos de Informação:

a) Núcleos Básicos de Informação Tecnológica: com atuação horizontal e especializados em um tipo de documento (normas, patentes) ou assuntos de interesse amplo (conservação de energia);

b) Núcleos Setoriais de Informação Tecnológica: voltados para o atendimento de setores industriais específicos;

c) Núcleos Regionais de Informação Tecnológica: com atuação em uma determinada região, atendendo usuários de diferentes setores industriais.

Atualmente, as três estruturas citadas pelo autor e surgidas na década de 1980 encontram-se difundidas em todo o território nacional, atendendo as peculiaridades de cada ICT, conforme previsão legal.

A proteção e transferência de tecnologias desenvolvidas em instituições de ciência, tecnologia e inovação ainda é insipiente, quando comparada à produção científica existente no País, o que demonstra que os NIT tem grande trabalho pela frente na promoção da cultura inovadora e proteção dos frutos desse processo de inovação.

Corroborando com essa afirmação, o Figueira et al (2013, p. 233) apresentam estudo no qual está demonstrado que, no período de 2005 a 2011, na Universidade Estadual de Santa Cruz (Bahia) foram encontradas 918 publicações científicas, ao passo que, no mesmo período, foram pedidas apenas 18 patentes pela instituição.

Essa disparidade entre o número de publicações científicas e pedidos de patentes evidencia a necessidade de maior interação entre o setor produtivo e o acadêmico, uma vez que, no Brasil, é comum que os pesquisadores estejam "fechados" na área acadêmica e afastados das indústrias.

Conforme dados do MCTI (2015), em tabela apresentando o percentual de pesquisadores por setor (empresas, governo e ensino superior), desconsiderando o setor privado sem fins lucrativos, o Brasil, em 2010, apresentava 25,9\% de seus pesquisadores nas empresas, 5,5\% no governo e 67,8\% no ensino superior. Em países que estão focados no desenvolvimento tecnológico os percentuais são opostos, com a maior parte dos pesquisadores nas empresas, como ocorre na Coreia, que, no mesmo período, possuía 76,5\% de seus pesquisadores nas empresas, $7,5 \%$ no governo e $14,9 \%$ no ensino superior, e na China, que possuía $61,1 \%$ dos pesquisadores nas empresas, $19,1 \%$ no governo e $19,8 \%$ no ensino superior.

De igual forma, é necessário também que haja a interação com o governo, visto que, conforme Castro e Souza (2012, p. 126), “no Brasil, o governo é responsável por 60,2\% do 
total dos gastos nacionais com Pesquisa e Desenvolvimento (P\&D), enquanto os outros 39,8\% são provenientes de capital privado."

Para promover esta grande interação entre academia, governo e indústria, a Lei estabeleceu algumas competências mínimas para os NIT.

Assim dispunha a Lei de Inovação em sua redação original:

Art. 16. A ICT deverá dispor de núcleo de inovação tecnológica, próprio ou em associação com outras ICT, com a finalidade de gerir sua política de inovação. Parágrafo único. São competências mínimas do núcleo de inovação tecnológica: I - zelar pela manutenção da política institucional de estímulo à proteção das criações, licenciamento, inovação e outras formas de transferência de tecnologia; II - avaliar e classificar os resultados decorrentes de atividades e projetos de pesquisa para o atendimento das disposições desta Lei;

III - avaliar solicitação de inventor independente para adoção de invenção na forma do art. 22;

IV - opinar pela conveniência e promover a proteção das criações desenvolvidas na instituição;

V - opinar quanto à conveniência de divulgação das criações desenvolvidas na instituição, passíveis de proteção intelectual;

VI - acompanhar o processamento dos pedidos e a manutenção dos títulos de propriedade intelectual da instituição. (BRASIL, 2004a)

Esta gama de competências e responsabilidades atribuídas aos NIT originalmente estão alinhadas aos ditames constitucionais, especialmente quanto ao objetivo fundamental de garantir o desenvolvimento nacional (art. $3^{\circ}$, inc. II da Constituição Federal) e, ainda, a manutenção da soberania da República (art. $1^{\text {o }}$, inc. I da Constituição Federal).

Neste sentido, denota-se o interesse nacional a respeito dos problemas típica e intrinsecamente brasileiros e, ainda, sob um enfoque político, pela manutenção da soberania nacional (BARBOSA: 2013, p. 436).

Na próxima seção serão demonstradas as principais alterações na lei de inovação, trazidas pela Lei $\mathrm{n}^{\mathrm{o}} 13.243$, de 2016, no que concerne aos NIT.

\section{ALTERAÇÕES TRAZIDAS PELA LEI n 13.243, de 2016, PARA OS NIT}

A principal mudança na Lei da Inovação, no que concerne aos NIT está representada pelo aumento de competências mínimas previstas para o órgão, que anteriormente eram apenas seis, sendo acrescidas mais quatro às já existentes no Art. 16 da referida lei:

\footnotetext{
VII - desenvolver estudos de prospecção tecnológica e de inteligência competitiva no campo da propriedade intelectual, de forma a orientar as ações de inovação da ICT;

VIII - desenvolver estudos e estratégias para a transferência de inovação gerada pela ICT;

IX - promover e acompanhar o relacionamento da ICT com empresas, em especial para as atividades previstas nos arts. $6^{\circ}$ a $9^{\circ}$;

$\mathrm{X}$ - negociar e gerir os acordos de transferência de tecnologia oriunda da ICT.
} 
Antes de tratar de cada uma das novas atribuições dos NIT em subseções específicas, é importante apresentar as demais alterações trazidas pela lei que dizem respeito aos núcleos de inovação tecnológica.

O inciso VI, do Art. $2^{\circ}$, da Lei de Inovação prevê agora que os NIT podem ou não ter personalidade jurídica própria, fato que não está regulado na redação original da referida lei.

A institucionalização e gestão dos NIT deverão, obrigatoriamente, estar previstas nas políticas de inovação das ICT públicas, o que faz com que seja atribuída mais importância aos núcleos, que passam a integrar formalmente as políticas de inovação da instituições.

Além das competências mínimas para os NIT, previstas nos incisos I a X do Art. 16, da Lei de Inovação, os parágrafos $2^{\circ}$ a $5^{\circ}$ do mesmo artigo apresentam novas características dos núcleos, que concedem maior autonomia à sua gestão.

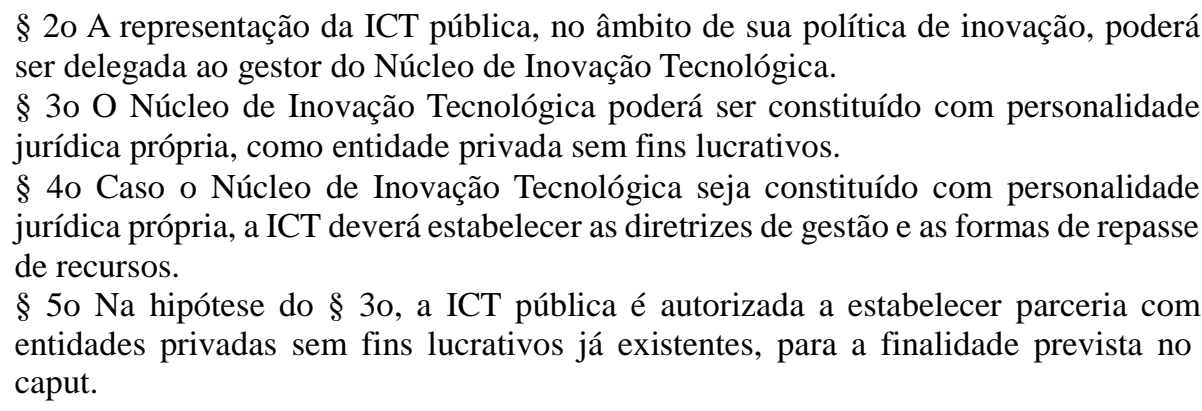

Tendo em vista que são alterações ainda muito recentes, ainda não é possível avaliar de que forma essas alterações impactarão nas atividades desenvolvidas nos NIT de forma prática.

\subsection{Estudos de Prospecção Tecnológica e Inteligência Competitiva no Campo da Propriedade Intelectual}

Dentre as novas atribuições mínimas dos NIT estão os estudos de prospecção tecnológica e de inteligência competitiva no campo da propriedade intelectual. Os dois institutos são correlatos, mas não sinônimos.

Conforme Figueira et al (2013, p. 230), a tentativa de "prospectar, ou explorar, o futuro é bem antiga para a humanidade, sendo que a prospecção como técnica utilizada no âmbito dos negócios ou da pesquisa científica, bem mais recente". Tal intento vem da necessidade de se posicionar proativamente em relação às perspectivas do futuro e pode ser conceituado como prospecção tecnológica.

A prospecção, portanto, é uma ferramenta utilizada para análises de sistemas sociais que permite estudar a situação presente, identificar tendências futuras e analisar o impacto do 
desenvolvimento científico e tecnológico da sociedade. Neste sentido, a prospecção não é uma mera utopia, ficção ou "adivinhação". Trata-se de uma parte da disciplina de "estudos de futuro", desenvolvida por organizações internacionais ao redor do mundo sob diversos enfoques, métodos, processos e resultados (Vásquez e Torres: 2008. p. 15)

Bahruth apud Antunes et al (2008, p. 56), aponta que o principal motivo de uma organização ou nação realizar estudos de prospecção tecnológica advém da necessidade de identificar os benefícios específicos que as tecnologias e suas consequentes inovações podem atender às demandas de determinada sociedade.

De outro lado, Antunes et al (2008, p. 57) acrescentam que a inteligência competitiva possui a finalidade de monitorar e fornecer informações diferenciadas para promover vantagens comparativas.

Conforme Teixeira e Souza (2013, p. 109), a inteligência competitiva "trata da análise das informações sobre o mercado e da geração de recomendações para os decisores dentro das empresas.” Tal processo tem a mesma finalidade dentro das ICT e tem por objetivo, tal e qual nas empresas, de minimizar os riscos dentro do processo decisório.

A respeito da relação entre prospecção tecnológica e inteligência competitiva, segue o entendimento de Teixeira e Souza (2013, p. 111):

\footnotetext{
A atividade de prospecção busca a identificação de informações e conhecimentos relevantes para os negócios da organização. Já a atividade de monitoramento, busca o acompanhamento das informações e dos conhecimentos produzidos e de relevância. As duas são, portanto, atividades complementares.
}

Percebe-se, portanto, que ambas as atividades devem realmente ser tratadas como complementares e, no âmbito das ICT, podem ajudar a na antevisão às futuras tendências tecnológicas e a buscar o melhor parceiro para a concepção o desenvolvimento e/ou produção das inovações pesquisadas no ambiente acadêmico. Neste contexto, cresce de importância a atuação dos NIT como elemento legal e institucional a impulsionar as atividades das ICT na definição das estratégias que melhor atendam às suas particularidades.

\subsection{Estudos de Estratégias para Transferência de Inovação}

De nada adianta a inovação se não sair das bancadas das universidades para os ambientes produtivos. Para que ocorra essa migração da academia para a indústria, é necessário que ocorra o processo de transferência de tecnologia desenvolvida na ICT.

Segundo o Ato Normativo No 135 do Instituto Nacional da Propriedade Industrial (INPI) os contratos de transferência de tecnologia compreendem a licença de direitos , 
mediante a exploração de patentes ou de uso de marcas, a aquisição de conhecimentos tecnológicos (fornecimento de tecnologia e prestação de serviços de assistência técnica e científica) e, ainda, os contratos de franquia.

De outro lado, Mattos e Guimarães (2012) mostram que depósito de patentes com a finalidade de licenciamento são uma alternativa para que as ICT realizem a transferência de tecnologia para o setor produtivo.

Cabe ressaltar que, sob o novo enfoque dado pelas alterações na Lei de Inovação, para que a tecnologia seja transferida, é necessário que seja feito um estudo do mercado, a fim de verificar se a comercialização do produto é viável e quem será o parceiro ideal para essa transferência. Essa deve ser uma preocupação tanto da ICT quanto da empresa.

Conforme Santana (2005, p. 63):

Contudo, antes de tomar a decisão pela realização da transferência de tecnologia, uma entidade deve realizar um diagnóstico tecnológico, a fim de saber se suas capacidades tecnológicas são adequadas para as exigências do mercado ou não. A partir da consequente elaboração de um planejamento tecnológico, novas tecnologias podem ser definidas como necessárias para a organização, podendo ser acessadas e obtidas de várias maneiras, dentre elas, a transferência de tecnologia.

Somente após o desenvolvimento de uma estratégia interna, poderá ser realizada a transferência da tecnologia desenvolvida na ICT, por intermédio de um contrato de transferência de tecnologia, que será analisado na subseção seguinte.

\subsection{Relacionamento das ICT com Empresas}

O relacionamento das ICT com as empresas deve ser muito bem estruturado, uma vez que cada ente tem seus objetivos específicos, que acabam coincidindo apenas no interesse de ambos pelo desenvolvimento tecnológico, mesmo que cada um continue com seus interesses particulares sobre esse desenvolvimento.

As empresas visam o lucro, o qual pode ser obtido com o desenvolvimento, produção e comercialização dos produtos e serviços, ao passo que as ICT tem seu interesse voltado prioritariamente para os resultados acadêmicos.

O inciso IX, do Art. 16, da Lei da Inovação determina que os NIT devem "promover e acompanhar o relacionamento da ICT com empresas, em especial para as atividades previstas nos arts. $6^{\circ}$ a $9^{\circ}$, , que serão analisados a seguir:

Art. $6^{\circ}$ É facultado à ICT pública celebrar contrato de transferência de tecnologia e de licenciamento para outorga de direito de uso ou de exploração de criação por ela desenvolvida isoladamente ou por meio de parceria. 
$\S 1^{\circ}$ A contratação com cláusula de exclusividade, para os fins de que trata o caput, deve ser precedida da publicação de extrato da oferta tecnológica em sítio eletrônico oficial da ICT, na forma estabelecida em sua política de inovação.

$\S 1^{\circ}$-A. Nos casos de desenvolvimento conjunto com empresa, essa poderá ser contratada com cláusula de exclusividade, dispensada a oferta pública, devendo ser estabelecida em convênio ou contrato a forma de remuneração.

$\S 2^{\circ}$ Quando não for concedida exclusividade ao receptor de tecnologia ou ao licenciado, os contratos previstos no caput deste artigo poderão ser firmados diretamente, para fins de exploração de criação que deles seja objeto, na forma do regulamento.

$\S 3^{\circ}$ A empresa detentora do direito exclusivo de exploração de criação protegida perderá automaticamente esse direito caso não comercialize a criação dentro do prazo e condições definidos no contrato, podendo a ICT proceder a novo licenciamento.

$\S 4^{\circ} \mathrm{O}$ licenciamento para exploração de criação cujo objeto interesse à defesa nacional deve observar o disposto no $\S 30$ do art. 75 da Lei no 9.279, de 14 de maio de 1996.

$\S 5^{\circ}$ A transferência de tecnologia e o licenciamento para exploração de criação reconhecida, em ato do Poder Executivo, como de relevante interesse público, somente poderão ser efetuados a título não exclusivo.

$\S 6^{\circ}$ Celebrado o contrato de que trata o caput, dirigentes, criadores ou quaisquer outros servidores, empregados ou prestadores de serviços são obrigados a repassar os conhecimentos e informações necessários à sua efetivação, sob pena de responsabilização administrativa, civil e penal, respeitado o disposto no art. 12.

$\S 7^{\circ} \mathrm{A}$ remuneração de ICT privada pela transferência de tecnologia e pelo licenciamento para uso ou exploração de criação de que trata o $\S 60$ do art. 5o, bem como a oriunda de pesquisa, desenvolvimento e inovação, não representa impeditivo para sua classificação como entidade sem fins lucrativos.

O Art. $6^{\circ}$ trata da possibilidade de a ICT pública realizar contratos de transferência de tecnologia para exploração ou licenciamento de criação desenvolvida pela própria ICT isoladamente, ou por intermédio de parcerias.

Essas parcerias podem advir de outras ICT, públicas ou privadas ou mesmo do setor privado, por intermédio de empresas, que poderá até mesmo ser contratada com cláusula de exclusividade. Todas esses detalhes dos contratos, que vão desde o início da parceria, com a definição da propriedade intelectual advinda da criação a ser desenvolvida conjuntamente, bem como a possibilidade de cláusula de exclusividade e possível licenciamento por parte dos detentores dos direitos de Propriedade Industrial devem ser propostos e acompanhados pelo NIT.

No Art. $7^{\circ}$ está previsto que a ICT poderá obter o direito de uso ou de exploração de criação protegida. Da mesma forma que as ICT podem comercializar suas criações, as mesmas também poderão obter direitos de uso ou de exploração de criações protegidas por outras entidades. Quando o inciso IX, do Art. 16 da Lei da Inovação determina que os NIT devem promover e acompanhar o relacionamento das ICT com as empresas, em especial nas atividades do Art. $7^{\circ}$, entende-se que os mesmos devem ter conhecimento de quais as 
empresas possuem as criações que são do interesse das ICT e devem promover a negociação para sua obtenção.

É um trabalho que passa desde a gestão do conhecimento, passando pela negociação, passando pela fase de confecção e análise dos contratos, sendo finalizada somente com o término do contrato, uma vez que o NIT deverá fiscalizar o contrato durante a sua vigência.

\begin{abstract}
Art. $8^{\circ} \quad$ É facultado à ICT prestar a instituições públicas ou privadas serviços técnicos especializados compatíveis com os objetivos desta Lei, nas atividades voltadas à inovação e à pesquisa científica e tecnológica no ambiente produtivo, visando, entre outros objetivos, à maior competitividade das empresas.

$\S 1^{\circ}$ A prestação de serviços prevista no caput dependerá de aprovação pelo representante legal máximo da instituição, facultada a delegação a mais de uma autoridade, e vedada a subdelegação. § 20 O servidor, o militar ou o empregado público envolvido na prestação de serviço prevista no caput deste artigo poderá receber retribuição pecuniária, diretamente da ICT ou de instituição de apoio com que esta tenha firmado acordo, sempre sob a forma de adicional variável e desde que custeado exclusivamente com recursos arrecadados no âmbito da atividade contratada. $\S 3^{\circ} \mathrm{O}$ valor do adicional variável de que trata o $\S 20$ deste artigo fica sujeito à incidência dos tributos e contribuições aplicáveis à espécie, vedada a incorporação aos vencimentos, à remuneração ou aos proventos, bem como a referência como base de cálculo para qualquer benefício, adicional ou vantagem coletiva ou pessoal.

$\S 4^{\circ} \mathrm{O}$ adicional variável de que trata este artigo configura-se, para os fins do art. 28 da Lei no 8.212, de 24 de julho de 1991, ganho eventual.
\end{abstract}

O Art. $8^{\circ}$ trata da prestação de serviços técnicos especializados "nas atividades voltadas à inovação e à pesquisa científica e tecnológica no ambiente produtivo, visando, entre outros objetivos, à maior competitividade das empresas."

Para tal, os NIT devem ser capazes de realizar a interface das ICT com as empresas, a fim de que os serviços especializados possam ser prestados de acordo com os interesses da instituição e em conformidade com a legislação em vigor.

Art. $9^{\circ}$ É facultado à ICT celebrar acordos de parceria com instituições públicas e privadas para realização de atividades conjuntas de pesquisa científica e tecnológica e de desenvolvimento de tecnologia, produto, serviço ou processo.

$\S 1^{\circ} \mathrm{O}$ servidor, o militar, o empregado da ICT pública e o aluno de curso técnico, de graduação ou de pós-graduação envolvidos na execução das atividades previstas no caput poderão receber bolsa de estímulo à inovação diretamente da ICT a que estejam vinculados, de fundação de apoio ou de agência de fomento.

$\S 2^{\circ}$ As partes deverão prever, em instrumento jurídico específico, a titularidade da propriedade intelectual e a participação nos resultados da exploração das criações resultantes da parceria, assegurando aos signatários o direito à exploração, ao licenciamento e à transferência de tecnologia, observado o disposto nos $\S \S 4^{\circ}$ a $7^{\circ}$ do art. $6^{\circ}$.

$\S 3^{\circ}$ A propriedade intelectual e a participação nos resultados referidas no $\S 20$ serão asseguradas às partes contratantes, nos termos do contrato, podendo a ICT ceder ao parceiro privado a totalidade dos direitos de propriedade intelectual mediante compensação financeira ou não financeira, desde que economicamente mensurável.

$\S 4^{\circ} \mathrm{A}$ bolsa concedida nos termos deste artigo caracteriza-se como doação, não configura vínculo empregatício, não caracteriza contraprestação de serviços nem vantagem para o doador, para efeitos do disposto no art. 26 da Lei no 9.250, de 26 
de dezembro de 1995, e não integra a base de cálculo da contribuição previdenciária, aplicando-se o disposto neste parágrafo a fato pretérito, como previsto no inciso I do art. 106 da Lei no 5.172, de 25 de outubro de 1966.

Já o Art. $9^{\circ}$ trata dos desenvolvimentos de tecnologias, produtos ou serviços, em parcerias com instituições públicas ou privadas. Nesse caso, os NIT, de igual forma, devem ser capazes de promover e acompanhar o relacionamento das ICT com as empresas, a fim de que esse desenvolvimento e seus frutos sejam geridos, de acordo com os interesses das instituições de ensino.

A lei permite até mesmo que todos os direitos de propriedade intelectual sejam cedida ao parceiro privado, mediante compensação financeira ou não, o que necessita de grande habilidade dos negociadores, a fim de que não ocorram prejuízos para as ICT.

\subsection{Transferência de Tecnologia Oriunda da ICT}

A transferência de tecnologia deverá ser formalizada por intermédio de um contrato de transferência de tecnologia que, conforme Art. $2^{\circ}$ da Instrução Normativa $n^{\circ} 16$, de 18 de março de 2013, do Instituto Nacional de Propriedade Industrial (INPI) são os contratos de licenças de propriedade industrial, que podem ser de exploração de patentes, de desenho industrial ou uso de marcas, os contratos de aquisição de conhecimentos tecnológicos, podendo ser de fornecimento de tecnologia e de prestação de assistência técnica, bem como os contratos de franquia e os de licença compulsória para exploração de patentes.

A Lei $n^{\circ} 10.168$, de 2000 , em seu Art. $2^{\circ}$, $§ 1^{\circ}$, considera "contratos de transferência de tecnologia os relativos à exploração de patentes ou de uso de marcas e os de fornecimento de tecnologia e prestação de assistência técnica."

Conforme a nova redação da Lei da Inovação, os NIT deverão ter capacidade de negociar e gerir estes contratos, o que gera a necessidade de um corpo técnico e jurídico com capacidade de formular contratos eficientes e de fiscalizar a execução desses contratos, a fim de verificar se os mesmos estão de acordo com as cláusulas contratuais.

Para Veigas (2007, p. 58-59), a elaboração de um contrato de tecnologia exige que o advogado possua entendimento, conhecimento e sensibilidade. O entendimento é necessário para compreender as necessidades estratégicas da entidade. O conhecimento é necessário para a elaboração de contratos de acordo com as normas em vigor e diante da necessidade de averbação desses contratos pelo INPI. Já a sensibilidade será necessária para a participação em "negociações - muitas vezes com partes estrangeiras - nas quais as questões de língua, 
valores e comportamentos devem ser assimilados e aceitos e muito respeito deve ser demonstrado para com as diferenças culturais."

Apesar de cada contrato ter suas características específicas, que tornam a utilização de modelos de contratos padrão uma prática perigosa, Veigas (2007, p. 59-64) apresenta algumas características e cláusulas referentes ao sigilo, que devem estar presentes na maioria dos contratos de transferência de tecnologia. Quanto às características, para a autora, os contratos devem ser claros e completos, evitando a aglomeração desnecessária a fim de que, um único contrato não contenha, "na medida do possível, objetos diferentes, que tenham tratamentos cambiais, tributários e de exigências burocráticas diferentes." Sobre cláusulas referentes ao sigilo, que devem estar presentes nos contratos, a autora entende como essenciais a descrição das partes que se comprometem com o sigilo, o escopo do sigilo, os compromissos assumidos, o prazo, a cláusula penal e o foro e a lei aplicável.

\section{CONSIDERAÇÕES FINAIS}

A Lei $\mathrm{n}^{\mathrm{o}}$ 13.243, de 11 de janeiro de 2016, trouxe significativas alterações na Lei da Inovação, com acréscimo de novas atribuições mínimas para os NIT, que devem ser observadas com atenção pelos integrantes desses núcleos, a fim de que a lei seja cumprida e não ocorram prejuízos para as ICT. Tais alterações visam, ainda, otimizar a gestão de tecnologia e o processo de gestão da inovação, com o objetivo de tirar o maior proveito possível de um sistema que ainda encontra-se em fase de amadurecimento.

Em relação às novas competências mínimas dos NIT exigidas em decorrência do aumento do rol do Art. 16, cabem algumas observações de ordem prática para uma gestão de qualidade por parte das ICT.

Para a promoção de estudos nas áreas de prospecção tecnológica e inteligência competitiva, constata-se que cresceu de importância a necessidade de mão de obra especializada para realizar estas atividades. Estudar cenários futuros e vislumbrar possíveis nichos de atuação e mudanças de trajetória tecnológica são tarefas que não são triviais e, por conseguinte, demandam profissionais habilitados em cada setor que a ICT pretende introduzir produtos ou processos capazes de gerar inovação.

A mesma linha de raciocínio pode ser observada em relação a negociação e elaboração de contratos de tecnologia. Por se tratarem de instrumentos que possuem um objeto que requer bastante atenção para sua delimitação, os NIT deverão contar com pessoal experiente no assunto. Contratos de tecnologia que envolvem o desenvolvimento de produtos com 
potencial de inovação não possuem a costumeira padronização do bens de consumo já consolidados no mercado. Desta forma, a discussão das cláusulas contratuais não pode ser feita superficialmente pelos NIT, sob pena de comprometer a segurança jurídica e os interesses institucionais.

Por derradeiro, cabe ressaltar que as ICT estarão lidando com empresas que atuam no mercado e, por definição, possuem a finalidade a obtenção de lucros. Neste particular, não há qualquer tipo de insinuação quanto à boa-fé das empresas quando em negociação com as ICT. Entretanto, é importante que esteja sempre em mente que o objetivo da iniciativa privada é o lucro e esse será buscado ao máximo quando o aspecto financeiro estiver em jogo. Portanto, é importante que os NIT possuam dados consistentes levantados pela prospecção tecnológica e a inteligência competitiva, a fim de que os contratos possam ser vantajosos tanto para as empresas quanto para as ICT e os resultados sejam os que atendam da melhor forma ao interesse da sociedade.

\section{REFERÊNCIAS}

ANTUNES, Adelaide M. S.; CANONGIA, Cláudia; BAHRUTH, Eliane; TÚLIO, Hugo; PIO, Marcello; GIANINNI, Roberto G. Prospección tecnológica - gestión del conocimiento e inteligencia competitiva: modelos de gestión para toma de decisiones y construcción de futuro. In: Org.: VÁSQUEZ Javier Medina; TORRES, Jenny Marcela Sánchez. Sinergía entre la prospectiva tecnológica y la vigilancia tecnológica e inteligencia competitiva. Instituto Colombiano para el Desarrollo de la Ciencia y la Tecnología 'Francisco José de Caldas'. Bogotá: Colciencias Colombia, 2008.

BARBOSA, Denis Borges. Tratado da Propriedade Intelectual (Tomo I). $1^{\text {a }}$ ed. Rio de Janeiro: Lumen Juris, 2013.

BES, Fernando Trías de; KOTLER, Philip. A bíblia da Inovação. São Paulo: Leya, 2011.

. Uma introdução à propriedade intelectual. $2^{\mathrm{a}}$ ed. Rio de Janeiro: Lumen Juris,

2010. Disponível em: <http://www.denisbarbosa.addr.com/arquivos/livros/umaintro2.pdf> Acesso em: 01 setembro 2015.

BITTAR, Carlos Alberto. Direito de Autor. 5ª ed. Rio de Janeiro: Forense, 2013.

BRASIL. Congresso Nacional. Constituição da República Federativa do Brasil, de 05 de outubro de 1988.Constituição (1988).

Congresso Nacional. Emenda Constitucional no 85, de 26 de fevereiro de 2015. Altera e adiciona dispositivos na Constituição Federal para atualizar o tratamento das atividades de ciência, tecnologia e inovação. Brasília: 2015.

Congresso Nacional. Lei $\mathrm{n}^{\circ}$ 9.279, de 14 de maio de 1996. Regula direitos e obrigações relativos à propriedade industrial. Brasília: 1996. 
Congresso Nacional. Lei $n^{0} 9.609$, de 19 de fevereiro de 1998. Dispõe sobre a proteção da propriedade intelectual de programa de computador, sua comercialização no País, e dá outras providências. Brasília: 1998a.

Congresso Nacional. Lei $\mathrm{n}^{\mathrm{o}}$ 9.610, de 19 de fevereiro de 1998. Altera, atualiza e consolida a legislação sobre direitos autorais e dá outras providências. Brasília: 1998b.

Congresso Nacional. Lei $\mathrm{n}^{\circ}$ 10.973, de 2 de dezembro de 2004.Dispõe sobre incentivos à inovação e à pesquisa científica e tecnológica no ambiente produtivo e dá outras providências. Brasília: 2004a.

Ministério da Ciência, Tecnologia e Inovação. Secretaria de Desenvolvimento Tecnológico e Inovação. Política de propriedade intelectual das instituições científicas e tecnológicas do Brasil: Relatório FORMICT 2014 - Brasília: 2015a.

Ministério da Ciência, Tecnologia e Inovação. Distribuição percentual de pesquisadores em equivalência de tempo integral, por setores institucionais, de países selecionados, 2000-2013. 2015. Disponível em: <http://www.mct.gov.br/index.php/content/view/338912/Distribuicao_percentual_de_pesquis adores_em_equivalencia_de_tempo_integral_por_setores_institucionais_sup_1_sup_de_pais es_selecionados.html>. Acesso em 2016-03-23.

CASTRO, Biancca Scarpeline; SOUZA, Gustavo Costa de. O papel dos Núcleos de Inovação Tecnológica (NITs) nas universidades brasileiras. Liinc em Revista, v.8, n.1, março, 2012, Rio de Janeiro, $p$ 125-140. Disponível em: <http://revista.ibict.br/liinc/index.php/liinc/article/view/465>. Acesso em 2016-02-13.

CNI (Confederação Nacional da Indústria). Propriedade industrial aplicada: reflexões para o magistrado. Brasília: CNI, 2013.

FUGUEIRA, Willian de Araújo; SEGUNDO, Gesil S. A.; SOUZA, Caciane C.; AMIGO, Fernanda V. PROSPECÇÃO TECNOLÓGICA: uma comparação entre as publicações e os processos de proteção da propriedade industrial na UESC. In: Cadernos de Prospecção, 2013, vol.6, n.2, p.229-238. Disponível em: <http://www.portalseer.ufba.br/index.php/nit/article/view/11446/8269>. Acesso em: 2016-0222.

IDS - Instituto Dannemann Siemsen de Estudos Jurídicos e Técnicos. Comentários à lei de propriedade industrial. $3^{\text {a }}$ ed. Rio de Janeiro: Renovar, 2013.

MARTINS, Rubens de Oliveira. Os núcleos de inovação tecnológica como estratégia das políticas de inovação do MCT (2004-2010). Latin American Journal of Business

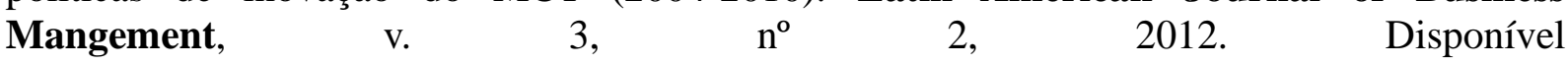
em:<http://www.lajbm.net/index.php/journal/article/view/95>. Acesso em: 05 jun. 2015.

MATTOS, João Roberto Loureiro; GUIMARÃES, Leonam dos Santos. Gestão da tecnologia e inovação: uma abordagem prática. $2^{a}$ ed. São Paulo: Saraiva. 2012. 
OCDE (Organização para Cooperação Econômica e Desenvolvimento). Manual de Oslo: Proposta de Diretrizes para Coleta e Interpretação de Dados sobre Inovação Tecnológica. OCDE: $1997 . \quad$ Disponível em <http://download.finep.gov.br/imprensa/manual_de_oslo.pdf>. Acesso em 31 agosto 2015

SANTANA, Elcio Eduardo de Paula. A transferência de tecnologia na USP: um estudo multicaso no Departamento de Física e Matemática e nas faculdades de medicina e odontologia - campus Ribeirão Preto - e nas empresas do setor de equipamentos médicos, hospitalares e odontológicos. 2005. Dissertação (Mestrado em Administração de Organizações) - Faculdade de Economia, Administração e Contabilidade de Ribeirão Preto, Universidade de São Paulo, Ribeirão Preto, 2005. Disponível em: <http://www.teses.usp.br/teses/disponiveis/96/96132/tde-21022006-142848/>. Acesso em: 2016-03-21.

TEIXEIRA, Renata Cristina; SOUZA, Renato Rocha. O uso das informações contidas em documentos de patentes nas práticas de Inteligência Competitiva: apresentação de um estudo das patentes da UFMG. In: Perspectivas em Ciência da Informação, v.18, n.1, p.106-125, jan./mar. Disponível em: 〈http://www.scielo.br/pdf/pci/v18n1/08.pdf>. Acesso em 2016-0120.

TIGRE, Paulo Bastos. Gestão da Inovação: a economia da tecnologia no Brasil. Rio de Janeiro: Elsevier, 2006.

VÁSQUEZ Javier Medina; TORRES, Jenny Marcela Sánchez. Introduccion: memoria de un esfuerzo colectivo. In: Org.: VÁSQUEZ Javier Medina; TORRES, Jenny Marcela Sánchez. Sinergía entre la prospectiva tecnológica y la vigilancia tecnológica e inteligencia competitiva. Instituto Colombiano para el Desarrollo de la Ciencia y la Tecnología 'Francisco José de Caldas'. Bogotá: Colciencias Colombia, 2008.

VIEGAS, Juliana L. B. Contratos típicos de propriedade industrial: contratos de cessão e de licenciamento de marcas e patentes; licenças compulsórias. p. 57-142. In: Contratos de propriedade industrial e novas tecnologias. Coord. SANTOS, Manoel J. Pereira dos; JABUR, Wilson Pinheiro.

XAVIER, Carlos Magno da Silva; XAVIER, Luiz Fernando da Silva; REINERT, Juliano Heinzelmann; STOECKICHT, Ingrid Paola. Gerenciamento de projetos de inovação, pesquisa e desenvolvimento (P\&D): uma adaptação da metodologia Basic Methodware. Rio de Janeiro: Brasport, 2014. 